\title{
HEXAMETHONIUM IN THE CHRONIC TREATMENT OF HYPER- TENSION-ITS EFFECT ON RENAL HEMODYNAMICS AND ON THE EXCRETION OF WATER AND ELECTROLYTES ${ }^{1}$
}

\author{
BY RALPH V. FORD, JOHN H. MOYER, AND CHARLES L. SPURR WITH THE TECHNICAL \\ ASSISTANCE OF C. POLK SMITH AND GEORGIA WELLER
}

\author{
(From the Departments of Medicine and Pharmacology, Baylor University College of Medicine \\ and the Medical Research Laboratory of the Veterans Administration Hospital, \\ Houston, Texas)
}

(Submitted for publication January 19, 1953; accepted July 7, 1953)

Neurogenic (autonomic) factors in hypertensive vascular disease $(1,2)$ may be studied with hexamethonium ${ }^{2}$ which reduces arterial blood pressure by blockade of the sympathetic ganglia. When the blood pressure is reduced acutely in this manner, alterations in renal hemodynamics have been observed. Following a single dose of hexamethonium administered parenterally to patients with hypertension, the glomerular filtration rate and renal plasma flow are immediately depressed but within one hour renal hemodynamic readjustment occurs and both functions return to or towards control values, although the arterial blood pressure remains depressed $(3,4)$ for two to six hours. The present study was designed to evaluate the effects of prolonged reduction of blood pressure in hypertensive patients, with and without renal damage, during the therapeutic oral administration of hexamethonium. In addition to studies in the supine position, observations on renal hemodynamics were made during ambulation before and during therapy. The latter observations were made in order to evaluate the effect of ganglionic blockade on the renal vasoconstriction which normally is associated with changing from the supine to the upright position (either static tilt or ambulation) in the untreated patient (5).

\section{METHODS}

Seven patients with hypertension were studied by measurements of glomerular filtration rate (inulin clearance), renal plasma flow (para-aminohippurate clearance), and maximum tubular excretory capacity ( $\mathrm{TmPAH}$ ). The rates of urine formation, sodium excretion, potassium excretion, and the changes in blood pressure were observed.

\footnotetext{
1 Supported in part by a grant from the National Institutes of Health, United States Public Health Service.

2 Supplied through the courtesy of Burroughs Wellcome and Company and Ciba Pharmaceutical Products, Inc.
}

The techniques of renal function and the methods of analysis have been previously described (3). The control determinations of glomerular filtration rate (GFR) and renal plasma flow (RPF) consisted of three consecutive 10minute periods in recumbency, followed by three periods in the ambulatory state. During the ambulatory studies the patients pushed the equipment mounted on a small table equipped with wheels. Following these six periods and after a 60 -minute equilibration and rest period in the recumbent position, three control determinations of GFR and TmPAH were performed. These were followed by three periods in the ambulatory state. The patients were then given hexamethonium orally four times daily to establish a reduction in mean blood pressure of $\mathbf{4 0}$ $\mathrm{mm}$. $\mathrm{Hg}$ or more when in the upright position. The second group of studies ("drug" studies) were done after one month or more and after at least seven days of consistent reduction of blood pressure. The renal function studies were then repeated in precisely the same fashion as the control studies, recumbent and ambulatory. Supine studies on GFR and RPF were done on an additional six patients (XM to XCa, Tables $\mathrm{I}$ and II) who were treated in a similar fashion. Determination of TmPAH was done on one patient in this latter group. Blood pressures were determined on the first seven patients with a sphygmomanometer and on the last six patients by intra-arterial manometry.

Observations on the effect of ambulation on electrolyte excretion were made on one additional patient (Table IV) who received hexamethonium as oral therapy for hypertension and who had an adequate response in blood pressure reduction in the upright position. He was studied in the metabolic ward and was given a constant diet in terms of calories $(2,300)$, protein (70 Gm.), sodium ( $800 \mathrm{mg}$. $\mathrm{NaCl}$ ), potassium (700 mg.), chloride (800 mg. $\mathrm{NaCl}$ ), and water $(3,000 \mathrm{ml}$.). After a five-day equilibration period, the urine was collected in four-hour periods for three consecutive days. It was analyzed for chloride, sodium, and potassium. The patient was ambulatory for three periods and recumbent for three periods during each day.

\section{RESULTS}

The patients required an average oral dose of $875 \mathrm{mg}$. of hexamethonium every six hours in or- 
der to obtain a consistent lowering of blood pressure. The percentile reduction in systolic pressure was equal to the percentile reduction in diastolic pressure. A typical study is summarized in Figure 1.

\section{Effect of oral hexamethonium on renal hemo- dynamics in the supine position}

Hexamethonium produced an average reduction of mean blood pressure (MBP) to 78 per cent of the control (from 162 to $127 \mathrm{~mm}$. $\mathrm{Hg}$ ) observations. This was not associated with a significant change in glomerular filtration rate (GFR) (98 per cent of control), maximum tubular excretory capacity for PAH (TmPAH) (95 per cent of control), or in renal plasma flow (RPF) (116 per cent of control). The constancy of renal blood flow
(RPF/1 minus hematocrit) (RBF) associated with a reduction in mean blood pressure is reflected in an average decrease in renal vascular resistance $(\mathrm{RVR}=\mathrm{MBP} / \mathrm{RBF})$ of 28 per cent (Table II).

\section{Effect of oral hexamethonium on renal hemo- dynamics during ambulation}

During the control studies (prior to hexamethonium administration) ambulation did not alter the mean blood pressure. However, there was evidence of renal vasoconstriction as reflected in a depression of GFR, RBF, and TmPAH and an increase in RVR. Ambulation, after hexamethonium administration, caused an additional reduction of MBP from 78 per cent to 65 per cent (127 to $104 \mathrm{~mm} . \mathrm{Hg}$ ) of the control $(162 \mathrm{~mm} . \mathrm{Hg}$ ) supine value (Table I). This was associated with
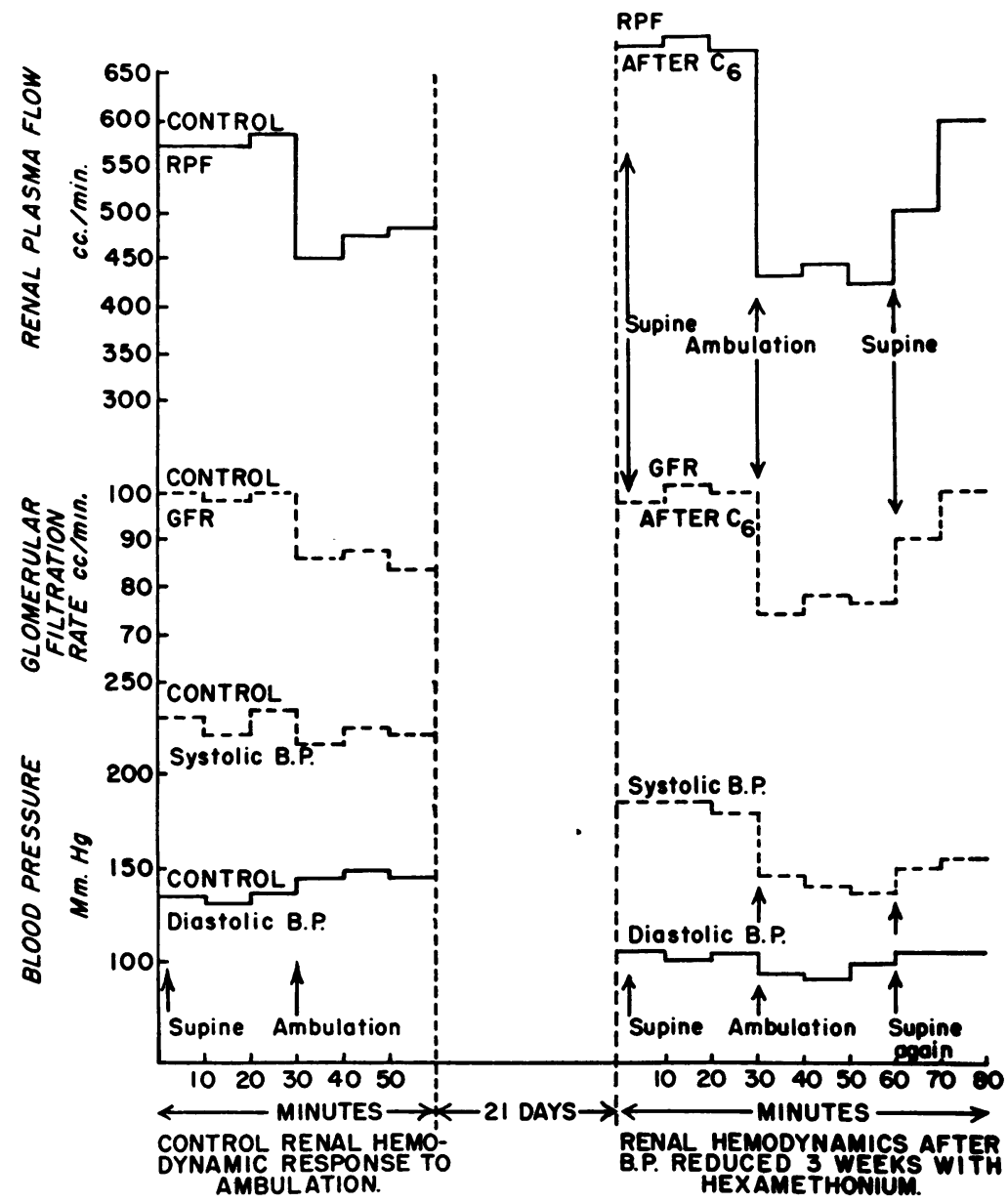

Fig. 1. A Typical (Patient WA, Table I) Renal Hemodynamic and Blood Pressure Response to Ambulation before and after Ganglionic Blockade with Hexamethonium 
TABLE I

Effect of oral hexamethonium on renal function

\begin{tabular}{|c|c|c|c|c|c|c|c|c|c|c|c|c|c|c|c|c|c|c|}
\hline \multirow[b]{2}{*}{ Pt. } & \multirow[b]{2}{*}{ Diagnosis* } & \multirow[b]{2}{*}{ Age } & \multicolumn{4}{|c|}{ Mean blood pressuret } & \multicolumn{4}{|c|}{$\begin{array}{l}\text { Glomerular filtration } \\
\text { rate }\end{array}$} & \multicolumn{4}{|c|}{ Renal plasma flow } & \multicolumn{4}{|c|}{$\begin{array}{l}\text { Tubular excretory } \\
\text { capacity }\end{array}$} \\
\hline & & & $C_{R}$ & $\mathrm{C}_{\mathrm{A}}$ & $\mathrm{D}_{\mathrm{R}}$ & $\mathbf{D}_{\mathbf{A}}$ & $C_{R}$ & $\mathbf{c}_{\mathbf{A}}$ & $\mathbf{D}_{\mathbf{R}}$ & $\mathbf{D}_{\mathbf{A}}$ & $C_{R}$ & $\mathbf{C}_{\boldsymbol{A}}$ & $\mathbf{D}_{\mathbf{R}}$ & $\mathbf{D}_{\mathbf{A}}$ & $\mathbf{C}_{\mathrm{R}}$ & $\mathbf{C}_{\mathbf{A}}$ & $\mathbf{D}_{\mathbf{R}}$ & $\mathbf{D}_{\mathbf{A}}$ \\
\hline & & & \multicolumn{4}{|c|}{$m m . \mathrm{Hg}$} & \multicolumn{4}{|c|}{ ml. per min. } & \multicolumn{4}{|c|}{ ml. per min. } & \multicolumn{4}{|c|}{ mg. per min. } \\
\hline $\begin{array}{l}\text { WA } \\
\text { AR } \\
\text { TE } \\
\text { JR } \\
\text { CA } \\
\text { JM } \\
\text { AB } \\
\text { XM } \\
\text { XH } \\
\text { XC } \\
\text { XB } \\
\text { XJ } \\
\text { XCa }\end{array}$ & $\begin{array}{l}\text { HVD } \\
\text { MHVD } \\
\text { HCVD } \\
\text { HVD } \\
\text { HCVD } \\
\text { HCVD } \\
\text { HVD } \\
\text { MHCVD } \\
\text { MHCVD } \\
\text { MHCVD } \\
\text { HVD } \\
\text { HVD } \\
\text { MHCVD }\end{array}$ & $\begin{array}{l}60 \\
62 \\
56 \\
58 \\
67 \\
60 \\
42 \\
54 \\
36 \\
42 \\
44 \\
54 \\
34\end{array}$ & $\begin{array}{l}156 \\
210 \\
160 \\
123 \\
147 \\
160 \\
160 \\
184 \\
150 \\
164 \\
178 \\
145 \\
175\end{array}$ & $\begin{array}{l}156 \\
220 \\
160 \\
133 \\
147 \\
150 \\
160\end{array}$ & $\begin{array}{l}120 \\
180 \\
130 \\
105 \\
120 \\
140 \\
140 \\
130 \\
120 \\
123 \\
110 \\
105 \\
126\end{array}$ & $\begin{array}{r}100 \\
130 \\
90 \\
85 \\
90 \\
110 \\
120\end{array}$ & $\begin{array}{r}100 \\
52 \\
90 \\
67 \\
78 \\
52 \\
74 \\
78 \\
74 \\
69 \\
93 \\
132 \\
67\end{array}$ & $\begin{array}{l}86 \\
45 \\
86 \\
73 \\
69 \\
33 \\
63\end{array}$ & $\begin{array}{r}99 \\
48 \\
83 \\
70 \\
81 \\
49 \\
64 \\
79 \\
84 \\
72 \\
86 \\
129 \\
65\end{array}$ & $\begin{array}{l}72 \\
25 \\
61 \\
72 \\
77 \\
42 \\
46\end{array}$ & $\begin{array}{l}572 \\
221 \\
445 \\
570 \\
728 \\
255 \\
355 \\
412 \\
332 \\
300 \\
520 \\
536 \\
175\end{array}$ & $\begin{array}{l}450 \\
179 \\
387 \\
509 \\
680 \\
177 \\
280\end{array}$ & $\begin{array}{l}697 \\
185 \\
477 \\
752 \\
631 \\
220 \\
383 \\
477 \\
412 \\
340 \\
610 \\
711 \\
313\end{array}$ & $\begin{array}{l}414 \\
112 \\
234 \\
367 \\
451 \\
174 \\
250\end{array}$ & $\begin{array}{l}66 \\
35 \\
72 \\
62 \\
83 \\
48 \\
77 \\
52\end{array}$ & $\begin{array}{l}56 \\
23 \\
71 \\
57 \\
85 \\
47 \\
62\end{array}$ & $\begin{array}{l}69 \\
40 \\
76 \\
58 \\
81 \\
41 \\
57 \\
43\end{array}$ & $\begin{array}{l}60 \\
28 \\
77 \\
53 \\
74 \\
33 \\
48\end{array}$ \\
\hline Mean & & & 162 & 161 & 127 & 104 & 79 & 65 & 78 & 56 & 417 & 380 & 478 & 286 & 62 & 57 & 58 & 53 \\
\hline \multicolumn{4}{|c|}{ Mean $\%$ of supine controlł } & 101 & 78 & 65 & & 88 & 98 & 77 & & 82 & 116 & 63 & & 89 & 95 & 83 \\
\hline
\end{tabular}

* HVD-hypertensive vascular disease

MHVD-malignant hypertensive vascular disease

HCVD-hypertensive cardiovascular disease

MHCVD-malignant hypertensive cardiovascular disease

$\dagger$ Mean blood pressure $=$ diastolic pressure plus one-third of the pulse pressure.

$\mathrm{C}_{\mathbf{R}}$-control recumbent

$\mathrm{C}_{\mathrm{A}}$-control ambulatory

$\mathrm{D}_{\mathrm{R}}$-drug recumbent

$\mathrm{D}_{\mathrm{A}}$-drug ambulatory

$\ddagger$ Mean value for per cent of control of individual patients-control $=100 \%$.

renal vasoconstriction and a reduction in renal functions (GFR, RPF, and TmPAH) which was more marked than with ambulation before the administration of hexamethonium. For example, ambulation caused an average decrease of 12 per cent in GFR during the control studies as compared to 23 per cent (from supine control) after hexamethonium. The RPF, which was not depressed by blood pressure reduction in the supine position, was reduced by ambulation (after hexamethonium) to 63 per cent of the supine control which was an additional decrease of 19 per cent from the ambulatory control. Ambulation caused an average reduction in TmPAH of 11 per cent during the control period as compared to 17 per cent (from 62 to $53 \mathrm{mg}$. per min.) after hexamethonium. Further evidence of renal vasoconstriction during ambulation after hexamethonium administration is found in the observation that there was a decrease in $\mathrm{RBF}$ of 37 per cent ( 725 to $501 \mathrm{ml}$. per min.) from the control supine value as compared to 15 per cent before hexamethonium. When the RBF in the supine position after hexamethonium is used as the reference point, the re- sponse to ambulation represents an even greater reduction (Table II). Ambulation after hexamethonium caused an average increase in RVR to only 105 per cent of the control, supine value. However, the percentage increase following ambulation is considerably greater when the post-drug supine value is used as the reference point.

\section{Effect of oral hexamethonium on water and electrolyte excretion}

Prior to hexamethonium administration, ambulation caused a reduction in urine volume and sodium excretion to 79 per cent and 75 per cent of the control supine observations, respectively, without a reduction in blood pressure. After ganglionic blockade and blood pressure reduction with hexamethonium, ambulation produced a further decrease in blood pressure by comparison to the supine post-drug value. This was associated with a sharp reduction in urine volume and in sodium excretion. The changes brought about by ambulation were of a somewhat greater magnitude (percentagewise) than those observed following ambu- 
TABLE II

Effect of oral hexamethonium on renal vascular resistance

\begin{tabular}{|c|c|c|c|c|c|c|c|c|c|c|c|c|}
\hline \multirow[b]{2}{*}{ Pt. } & \multicolumn{4}{|c|}{ Hematocrit* } & \multicolumn{4}{|c|}{ Renal blood flow } & \multicolumn{4}{|c|}{$\underset{\times 10^{4} \dagger}{\text { Renal vascistance }}$} \\
\hline & $\overline{C_{R}}$ & $\mathrm{C}_{\mathrm{A}}$ & $\mathrm{D}_{\mathrm{R}}$ & $\overline{D_{A}}$ & $\overline{C_{R}}$ & $\mathrm{C}_{\mathrm{A}}$ & $\overline{D_{R}}$ & $\overline{D_{A}}$ & $\overline{C_{R}}$ & $\mathrm{C}_{\mathrm{A}}$ & $\mathrm{D}_{\mathrm{R}}$ & $\overline{\mathrm{D}_{\mathrm{A}}}$ \\
\hline & \multicolumn{12}{|c|}{$m l_{.} / \min .=\frac{R P F}{1-H c l^{2}}$} \\
\hline $\begin{array}{l}\text { WA } \\
\text { AR } \\
\text { TE } \\
\text { JR } \\
\text { CA } \\
\text { JM } \\
\text { AB } \\
\text { XM } \\
\text { XH } \\
\text { XC } \\
\text { XB } \\
\text { XJ } \\
\text { XCa }\end{array}$ & $\begin{array}{l}45 \\
46 \\
45 \\
42 \\
45 \\
42 \\
41 \\
38 \\
44 \\
46 \\
40 \\
36 \\
41\end{array}$ & $\begin{array}{l}46 \\
47 \\
47 \\
43 \\
46 \\
46 \\
42\end{array}$ & $\begin{array}{l}38 \\
46 \\
43 \\
42 \\
41 \\
43 \\
41 \\
40 \\
43 \\
46 \\
41 \\
37 \\
40\end{array}$ & $\begin{array}{l}40 \\
48 \\
45 \\
43 \\
42 \\
46 \\
42\end{array}$ & $\begin{array}{r}1,040 \\
409 \\
809 \\
983 \\
1,324 \\
440 \\
602 \\
665 \\
593 \\
556 \\
867 \\
838 \\
297\end{array}$ & $\begin{array}{r}833 \\
338 \\
730 \\
893 \\
1,259 \\
328 \\
483\end{array}$ & $\begin{array}{r}1,124 \\
343 \\
837 \\
1,297 \\
1,069 \\
386 \\
649 \\
795 \\
723 \\
630 \\
1,034 \\
1,129 \\
522\end{array}$ & $\begin{array}{l}690 \\
215 \\
425 \\
644 \\
778 \\
322 \\
431\end{array}$ & $\begin{array}{l}150 \\
513 \\
198 \\
125 \\
111 \\
364 \\
266 \\
277 \\
253 \\
295 \\
205 \\
173 \\
589\end{array}$ & $\begin{array}{l}187 \\
651 \\
219 \\
149 \\
117 \\
457 \\
331\end{array}$ & $\begin{array}{r}107 \\
525 \\
155 \\
81 \\
112 \\
363 \\
216 \\
164 \\
166 \\
195 \\
106 \\
93 \\
241\end{array}$ & $\begin{array}{l}145 \\
605 \\
212 \\
132 \\
116 \\
342 \\
278\end{array}$ \\
\hline Mean & 42 & 45 & 42 & 44 & 725 & 695 & 811 & 501 & 271 & 302 & 194 & 261 \\
\hline \multicolumn{2}{|c|}{ Mean \% of control } & 103 & 98 & 100 & & 85 & 115 & 63 & & 120 & 72 & 105 \\
\hline
\end{tabular}

* See Table I for definition of symbols.

$\dagger$ Renal vascular resistance $=$ mean blood pressure $/$ renal blood flow .

lation during the control period. There was no change in potassium excretion due to ambulation (106 per cent of supine control) during the control period but after hexamethonium there was an apparent decrease to 79 per cent of the supine value during hexamethonium therapy.

The patients were given a constant sodium diet for two weeks prior to receiving hexamethonium and throughout the period of drug administration; yet, after one month of therapy, all but one of the patients showed a reduction in plasma sodium concentration. The lone exception was the only patient who did not show a decrease in the excretion of sodium in the post-drug supine state as compared to the control supine value. Despite the apparent decrease in sodium and water excretion during the studies which were performed after receiving hexamethonium for one month, none of the pa-

TABLE III

Effect of oral hexamethonium on water and electrolyte excretion

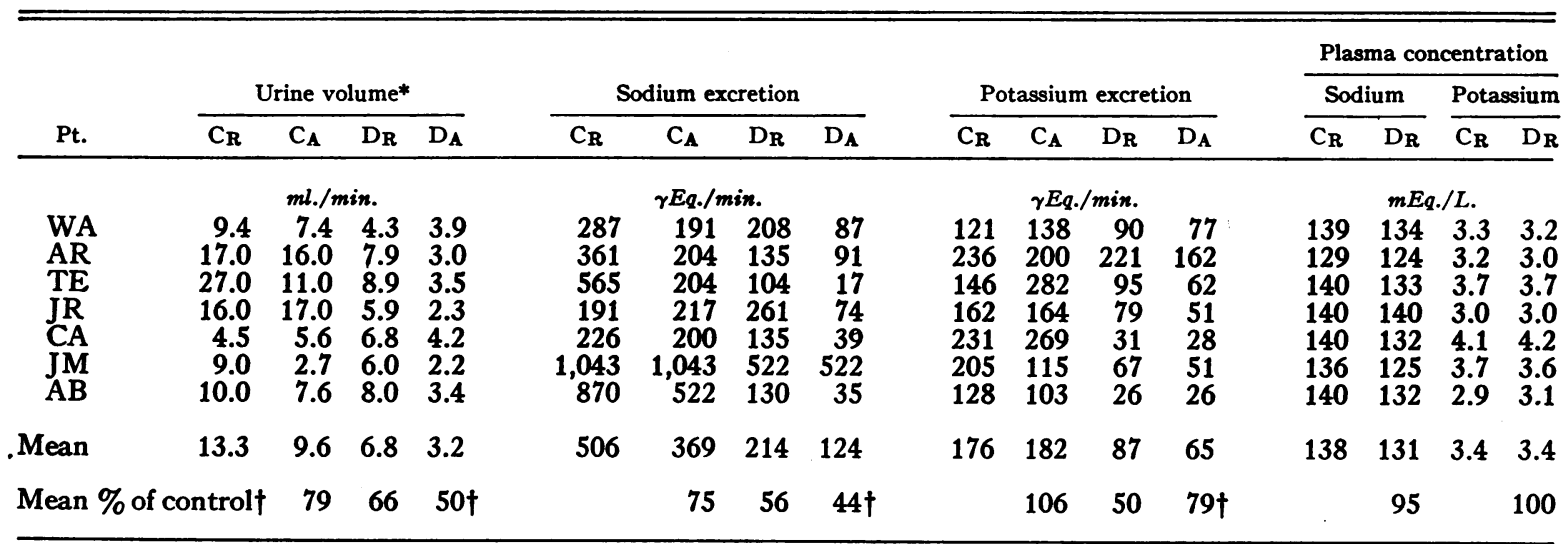

* See Table I for definition of symbols.

+ Mean \% of control-

$C_{A}=C_{A} / C_{R} \times 100$
$D_{B}=D_{B} / C_{R} \times 100$

$D_{R}=D_{R} / C_{R} \times 100$
$D_{A}=D_{A} / D_{R} \times 100$ 
TABLE TV

Comparative effect of ambulation and recumbency on water and electrolyte excretion in one patient under hexamethonium (oral) therapy*

\begin{tabular}{|c|c|c|c|c|c|c|}
\hline Day & Period & State & U.V. & $\mathrm{Cl}$ & $\mathrm{Na}$ & $\mathbf{K}$ \\
\hline $12-7-52$ & $\begin{array}{l}1 \text { ( }(7-11 \text { a.m.) } \\
2 \text { (11-3 p.m.) } \\
3 \text { (3-7 p.m.) } \\
4 \text { (7-11 p.m.) } \\
5 \text { (11-3 a.m.) } \\
6 \text { (3-7 a.m.) }\end{array}$ & $\begin{array}{l}\mathbf{A} \\
\mathbf{R} \\
\mathbf{A} \\
\mathbf{A} \\
\mathbf{R} \\
\mathbf{R}\end{array}$ & $\begin{array}{l}1.04 \\
5.17 \\
3.17 \\
1.96 \\
4.29 \\
2.33\end{array}$ & $\begin{array}{l}55 \\
83 \\
58 \\
38 \\
92 \\
98\end{array}$ & $\begin{array}{r}47 \\
333 \\
71 \\
42 \\
96 \\
63\end{array}$ & $\begin{array}{r}22 \\
225 \\
20 \\
18 \\
75 \\
23\end{array}$ \\
\hline $12-8-52$ & $\begin{array}{l}1 \text { (7-11 a.m.) } \\
2 \text { (11-3 p.m.) } \\
3 \text { (3-7 p.m.) } \\
4 \text { (7-11 p.m.) } \\
5 \text { (11-3 a.m.) } \\
6 \text { (3-7 a.m.) }\end{array}$ & $\begin{array}{l}\mathbf{A} \\
\mathbf{R} \\
\mathbf{A} \\
\mathbf{A} \\
\mathbf{R} \\
\mathbf{R}\end{array}$ & $\begin{array}{l}0.79 \\
4.21 \\
2.46 \\
2.50 \\
3.46 \\
1.96\end{array}$ & $\begin{array}{r}29 \\
108 \\
79 \\
55 \\
88 \\
79\end{array}$ & $\begin{array}{r}34 \\
138 \\
58 \\
63 \\
75 \\
63\end{array}$ & $\begin{array}{r}10 \\
208 \\
221 \\
38 \\
58 \\
19\end{array}$ \\
\hline $12-9-52$ & $\begin{array}{l}1 \text { ( }(7-11 \text { a.m.) } \\
2 \text { (11-3 p.m.) } \\
3 \text { (3-7 p.m.) } \\
4 \text { (7-11 p.m.) } \\
5 \text { (11-3 a.m.) } \\
6 \text { (3-7 a.m.) }\end{array}$ & $\begin{array}{l}\mathbf{A} \\
\mathbf{R} \\
\mathbf{A} \\
\mathbf{A} \\
\mathbf{R} \\
\mathbf{R}\end{array}$ & $\begin{array}{l}1.08 \\
5.54 \\
1.38 \\
1.63 \\
4.42 \\
1.67\end{array}$ & $\begin{array}{r}80 \\
107 \\
37 \\
48 \\
100 \\
89\end{array}$ & $\begin{array}{r}58 \\
304 \\
29 \\
42 \\
154 \\
42\end{array}$ & $\begin{array}{r}29 \\
254 \\
8 \\
14 \\
92 \\
12\end{array}$ \\
\hline
\end{tabular}

* State: A-ambulatory; R-recumbent

U.V.: Urine volume ( $\mathrm{ml} . / \mathrm{min}$.)

$\mathrm{Cl}$ : Chloride excretion ( $\gamma \mathrm{Eq} . / \mathrm{min}$.)

$\mathrm{Na}$ : $\quad$ Sodium excretion ( $\gamma$ Eq./min.)

K: $\quad$ Potassium excretion ( $\gamma$ Eq./min.)

tients gained weight nor did they demonstrate signs of edema to indicate salt and water retention.

The results of the electrolyte excretion studies during alternating four-hour recumbent and ambulatory periods in one patient are indicated in Table IV. Observations were made on the excretion rates of water, sodium, chloride, and potassium. These excretion rates were depressed in the four-hour periods of ambulation but were augmented in the four-hour periods of recumbency which immediately followed the period of ambulation. The excretion rates of water and electrolytes decreased during the second four-hour period when two collection periods were run consecutively in the recumbent position.

\section{DISCUSSION}

Since hexamethonium may be used orally in long term therapy of hypertension, it is of interest to observe the changes in homeostatic balances which occur. Previous work has demonstrated that a single intravenous dose of hexamethonium is followed by a prolonged reduction in arterial pressure but only a temporary depression of glomerular filtration rate (GFR) and renal plasma flow (RPF) in the recumbent position. The present data indicate a continuation of this response during prolonged oral hexamethonium therapy. There was no depression of GFR, RPF, or TmPAH in the supine position, although the blood pressure was significantly reduced. This was reflected in a reduction of renal vascular resistance. Preexistent renal damage did not appear to alter this response. These observations are in agreement with the observations of Corcoran, Taylor, and Page (6) who observed an increase in RPF and a decrease in MBP following spinal anesthesia and suggest that in patients with hypertension a significant degree of renal vasoconstriction may be mediated over the sympathetic nervous system.

TABLE $\mathbf{V}$

Summary of the effect of ambulation before and after oral hexamethonium in seven patients (Mean values and percentile changes)* $\dagger$

\begin{tabular}{|c|c|c|c|c|c|c|c|c|}
\hline & $C_{R}$ & $c_{\boldsymbol{A}}$ & $\mathrm{C}_{\mathbf{X} / 0^{\circ}}$ & $\mathrm{D}_{\mathbf{R}}$ & $\underset{\times 10^{\circ}}{\mathrm{D}_{\mathrm{R}} / \mathrm{C}_{\mathrm{R}}}$ & $\mathrm{D}_{\mathbf{A}}$ & $\underset{\times 10^{\circ}}{D_{A} / C_{R}}$ & ${ }_{\times 10^{2}}^{D_{A} / D_{R}}$ \\
\hline $\begin{array}{l}\text { Mean blood pressure (mm. Hg) } \\
\text { Glomerular filtration rate (ml./min.) } \\
\text { Renal plasma flow (ml./min.) } \\
\text { Tubular excretory capacity (mg./min.) } \\
\text { Hematocrit } \\
\text { Renal blood flow (ml./min.) } \\
\text { Renal vascular resistance } \times 10^{3} \\
\text { Urine volume (ml./min.) } \\
\text { Sodium excretion ( } \gamma \text { Eq./min.) } \\
\text { Potassium excretion ( } \gamma \text { Eq./min.) }\end{array}$ & $\begin{array}{r}159 \\
73 \\
449 \\
63 \\
44 \\
801 \\
247 \\
13.3 \\
506 \\
176\end{array}$ & $\begin{array}{r}161 \\
65 \\
380 \\
57 \\
45 \\
695 \\
302 \\
9.6 \\
369 \\
182\end{array}$ & $\begin{array}{r}101 \\
89 \\
85 \\
90 \\
102 \\
87 \\
122 \\
72 \\
73 \\
103\end{array}$ & $\begin{array}{r}134 \\
71 \\
478 \\
60 \\
42 \\
815 \\
223 \\
6.8 \\
214 \\
87\end{array}$ & $\begin{array}{r}84 \\
97 \\
106 \\
95 \\
95 \\
102 \\
90 \\
51 \\
42 \\
49\end{array}$ & $\begin{array}{r}104 \\
56 \\
286 \\
53 \\
44 \\
501 \\
261 \\
3.2 \\
124 \\
65\end{array}$ & $\begin{array}{r}65 \\
77 \\
64 \\
84 \\
100 \\
63 \\
106 \\
= \\
\overline{37}\end{array}$ & $\begin{array}{r}78 \\
79 \\
60 \\
88 \\
105 \\
61 \\
117 \\
47 \\
58 \\
75\end{array}$ \\
\hline
\end{tabular}

* All values are mean values for seven patients (WA to $A B$ ) who were studied both in the supine position and during ambulation.

$\uparrow \mathrm{C}_{\mathrm{B}}-$ Control recumbent

$\mathrm{C}_{\mathrm{A}}$-Control ambulatory

$D_{R}$-Recumbent after hexamethonium

$\mathrm{D}_{\mathbf{A}}$-Ambulatory after hexamethonium 
The participation of neurogenic reflexes in the control of renal functions is suggested by the changes accompanying tilting (5) or ambulation as summarized in Table $\mathrm{V}\left(\mathrm{C}_{\mathbf{A}} / \mathrm{C}_{\mathbf{R}}\right)$. Renal vasoconstriction occurs as evidenced by the increase in RVR and a decrease in GFR, RBF, and $\mathrm{TmPAH}$, but minimal, if any, change in blood pressure. This is associated with a decrease in the excretion of water and sodium. During hexamethonium therapy, there is an additional reduction in blood pressure due to ambulation which is also accompanied by a reduction in GFR, $\mathrm{RBF}$, TmPAH, and the excretion of water, sodium, and potassium (Table $V, D_{\Delta} / D_{R}$ ). There is very little increase in RVR in the ambulatory state after hexamethonium as compared to the recumbent state before the drug is administered $\left(D_{A} / D_{R}\right)$. However, when the recumbent state after ganglionic blockade is used as the baseline there is nearly as great a percentile increase in RVR due to ambulation as there was in the untreated patient (Table $V, D_{\Delta} / D_{R}$ as compared to $C_{\Delta} / C_{R}$, respectively). This indicates that under the stress of postural changes, reflex vasoconstrictive mechanisms in the kidney are retained despite partial ganglionic blockade with hexamethonium. In spite of the (apparent) depression of renal hemodynamics during ambulation there was no instance of increased renal decompensation as manifested by a rising blood urea nitrogen.

The explanation for the depression of water and electrolyte excretion during hexamethonium therapy is not apparent. Even during recumbency, the present data show a decrease in water and sodium excretion during hexamethonium therapy as compared to the control observations. The reduction in plasma sodium concentration suggests a partial depletion of this electrolyte during the administration of hexamethonium. A depleted state due to sodium loss during the initial administration of hexamethonium might be reflected in decreased excretion of sodium in the urine after receiving hexamethonium for prolonged periods (one month or more). The initial response to hexamethonium administration was not studied since this observation on sodium excretion was not anticipated. Variations in sodium and water intake between the control study and one month later may also be responsible for the reduced sodium excretion since sodium intake was not rigidly controlled in these patients.
The amount of sodium in the diet was kept constant during the study and for a two-week control period before the drug was administered. However, one cannot be sure that the patients consumed their entire diet. This may well be a factor since initial therapy with hexamethonium is frequently associated with a decreased appetite. Before any conclusions are drawn in this regard the problem should be investigated in more detail and the observations confirmed by other investigators.

The acute response to ambulation may well be a neurogenic response, since neurogenic impulses to the kidney may cause an increase in tubular reabsorption of water and sodium. There is evidence to indicate that it is not of hormonal origin since Murphy and Stead (7) have shown that endogenous antidiuretic hormone does not increase sodium reabsorption in man. In spite of the apparent depression of excretion of water and electrolytes, none of the patients exhibited edema or other signs of fluid retention. In one patient studied by observations of excretion rates of water, sodium, potassium, and chloride during four-hour periods at which time he was either ambulatory or recumbent, there was a decrease in excretion during ambulation but an increase during recumbency. During the sleeping hours, excretion of sodium and water during the first (11 to 3 a.m.) recumbent period was greater than the second ( 3 to 7 a.m.) consecutive recumbent period, suggesting that during the first sleeping period there was an augmented excretion to compensate for the preceding period of depressed excretion. Although renal functions are depressed during ambulation, there is a return to the control values during recumbency even though the blood pressure is reduced during hexamethonium therapy. Thus, this period during recumbency may also allow for necessary homeostatic balance or compensation to prevent retention of renal excretion products such as urea nitrogen.

\section{SUM MARY AND CONCLUSIONS}

1. Thirteen patients with hypertension have been observed during oral hexamethonium therapy. Observations were made during recumbency as well as during ambulation.

2 . In the supine position, there was a reduction in blood pressure after hexamethonium without a reduction in renal plasma flow, glomerular filtration rate, or tubular excretory capacity. These 
observations indicate that the renal vessels in patients with hypertension are quite capable of dilating.

3. In the ambulatory state before hexamethonium, there was a depression of glomerular filtration, renal plasma flow, and TmPAH due to vasoconstriction. After hexamethonium therapy, the ambulatory state was accompanied by a further drop in blood pressure and a reduction in renal functions quite similar to those observed in the untreated patient but the changes were often more marked.

4. Ambulation after the administration of hexamethonium is accompanied by a decrease in the excretion of water, sodium, and potassium. This may be due to neurogenic impulses as suggested by the depression during ambulation alone without a drop in blood pressure.

5. Hexamethonium when used orally in the chronic treatment of hypertension appears to be acceptable since none of the changes described resulted in any significant alteration of their clinical status in terms of impaired excretion of nitrogenous substances or in the retention of sodium and water. Reactivity in the recumbent position seems to compensate for the depressed function during ambulation.

\section{REFERENCES}

1. Ferris, E. B., Reiser, M. F., Stead, W. W., and Brust, A. A., Jr., Clinical and physiological observations of interrelated mechanisms in arterial hypertension. Tr. A. Am. Physicians, 1948, 61, 97.

2. Gregory, R., and Levin, W. C., Studies on hypertension. V. Effect of high spinal anesthesia on the blood pressure of patients with hypertension and faradvanced renal disease, its possible relationship to pathogenesis of hypertension. J. Lab. \& Clin. Med., 1945, 30, 1037.

3. Moyer, J. H., and Mills, L. C., Hexamethonium-its effect on glomerular filtration rate, maximal tubular function, and renal excretion of electrolytes. J. Clin. Invest., 1953, 32, 172.

4. Mills, L. C., and Moyer, J. H., The effect of hexamethonium on renal hemodynamics in normotensive and hypertensive human subjects. Am. J. M. Sc., 1953, 226, 1.

5. Moyer, J. H., Mills, L. C., and Ford, R. V., The effect of head-up tilted position on renal hemodynamics and water and electrolyte excretion in patients with hypertension and renal damage. In preparation.

6. Corcoran, A. C., Taylor, R. D., and Page, I. H., Circulatory responses to spinal and caudal anesthesia in hypertension: relation to the effect of sympathectomy. II. Effect on renal function. Am. Heart J., 1948, 36, 226.

7. Murphy, R. F. J., and Stead, E. A., Jr., Effects of exogenous and endogenous posterior pituitary antidiuretic hormone on water and electrolyte excretion. J. Clin. Invest., 1951, 30, 1055. 